\title{
Research on the Application of Multi-sound Viewing on Music Teaching
}

\section{Yong Zhi}

School of music and dance, Ningxia Teachers' University, the Ningxia Hui Autonomous Region, 756000

Keywords: multi-sound viewing; Music teaching; application

\begin{abstract}
As a discipline that intersects, blends, and interrelates with other disciplines in music, solfeggio is a required course for music learners and music lovers, as well as a stepping stone for learning music. The practice of solfeggio is present in the learning process of each music discipline. The most important purpose of learning to sing and practice is to lay a solid foundation for their own professional studies and to establish a good inner auditory and musical perception abilities for music majors. As a very important part of this, auditioning is a musical basic and musical skill that every student learning music must have to learn. Improving visual abilities has a very important role in the training of musical elements such as beats, rhythms, pitches, and musical sensations in the course of teaching practice.
\end{abstract}

\section{Introduction}

As a professional basic course and required course in music learning process, the solfeggio training course combines almost all music course contents such as vocal music, music theory, piano and composition techniques, and is a cross-cutting lesson. Usually, we say that learning to sing and listening to the ear is a stepping stone for learning music lessons, and it is a necessary means to build a student's inner hearing and guide students to obtain the correct musical aesthetic ability. The solfeggio course is composed of two parts: the vocalist and the ear-trainer. As one of the important parts, the audition is a musical foundation and skill that each music student must possess and learn. With the constant advancement of the discipline and the continuous deepening of research, simple monophonic vocals can no longer meet the requirements of music students in training for music and sound and hearing, and more and more students are beginning to sing around in multiple voices. Learn and train. Multi-speaking is an advanced stage in the practice of singing. The multi-sounding training plays an important role in cultivating students' musical perception ability, harmony listening ability, and building a three-dimensional musical thinking model. . In recent years, as the demand for music research and discipline development has been increasing year by year, the quality of students' music has been continuously improved. Due to its rich content and diverse forms, multi-sounding vocals have been increasingly valued by music educators. In the near future, it will certainly become the main teaching content in the solfeggio lesson.

\section{Kinds of Multi-part Voice}

Multi-sounding is a multi-level musical art expression form. It is formed by adding multiple voices on the basis of monophonic melody, thus forming a three-dimensional harmony relationship and forming rich multi-line music. . The most important part of the multi-sight singing is the two, three, and four voices, and there are also six or eight or more voices (in this article, six, eight, etc. more Collectively referred to as four or more voices). The two-part violin is generally composed of the soprano and bass components; the three-parameter violin is composed of soprano, tenor, and bass components; the four-parameter violin is composed of soprano, alto, tenor, and male. Bass voice components. Therefore, in the course of conducting multi-sounding vocal lessons, teachers should also pay attention to grouping training according to the students' vocal level and the actual situation of voice. The melodic soprano part is usually used for the singing of the melody part, and the other part is for the singing part and the harmony part. The roots of the parts of the harmony and bass parts are as solid and powerful as the trunk, supporting the balance of the upper part, so the 
bass part has higher requirements for students' level of sight. In the training of multi-part violins, the vocalists of each part are required to coordinate with each other. While melodizing the melody of the sound part, they must also take into account the other parts. The ear must hear the melody of other parts. In order to achieve the balance between the voice. The form of the multi-vocal part has harmony and polyphony, as well as a combination of harmony and polyphony. It contains all the elements of musical techniques and techniques, from pitch, tone, beat, and sound zone. , melody, rhythm, chords, tune, divorced, transfer, phrase, music, genre, song, harmony texture, inner emotions. In particular, it is horizontal and vertical, three-dimensional staggered music lines, greatly enriched the performance and appeal of musical works, but also increased the technical difficulty of the performance.

The two-voice view can be said to be the simplest multi-part visual lyrics. It is the basis of multi-part lyrics, and can be said to be a watershed between single-part vocals and multiple vocals. When the music auditory is directed to the multi-part sound, we seem to be able to cope with only the psychological level of "perceived," and when the two voices (and more voices) act on the music, the "thinking" becomes more At a higher level, it plays an important role in guiding, grooming, and analyzing. Two-voice visual singing is usually divided into harmony and polyphony. Harmony polyphony is intended to emphasize the sense of harmony in the longitudinal pitch, while polyphony vocals emphasize the sensation of the horizontal melody. Two-voice sightings are also the most important part of multi-part violin singing. The two-part visual sing not only balances the relations between the various parts, but also understands and understands the tonal harmony, and at the same time it can promote the accuracy of the vocal notes in the single part and increase the expressiveness. It is also a three-part and four-part voice. The entrance of sight-seeing lays a good foundation.

\section{Pitch Training}

The quintessence of the solfeggio training course is to train students' ability to read the spectrum. The phonological criteria are the basic conditions for the ability to read the spectrum. Without the pitch, there is no music in our hearts. When you get a multi-sound part of the lyrics, the first thing to do is to read the spectrum accurately and have a preliminary understanding of the melody of your voice in the mind. The horizontal melody pitch and the vertical and horizontal sounds are all needed. To solve the problem, only the pitch accuracy guarantees that the training of multi-vocal visual sings can be performed smoothly. Without accurate pitches, complete lyrics cannot be interpreted. Therefore, the pitch is the basis of the multi-part voice. An important part of multi-sounding vocal training is the integration of sounds between vocal parts, and the important prerequisite for ensuring good harmony and harmony is the pitch. In multi-sounding vocal training, sometimes only one pitch of a vocal part has a problem, and it will change the harmony of the entire work. For example, major chords appear in the work. If the middle part sings the three-tone sound and lowers the semitone, then the third major chord becomes a small three-chord chord. The original bright and powerful color becomes soft and lyrical, and the visual work will be performed. This color and the author's emotions have been completely tampered with. Therefore, inaccuracy is a precondition for the achievement of sound and harmony in multi-part visual lyric works.

The relationship between pitch and multi-part voice can be said to be interconnected and interrelated. From the single-sighted part to the multi-part part, the sound harmony will be affected by the pitch. The multi-speaking singer training also improves the student's pitching ability. The students perceive the sensation of fusion of other individual parts based on the monosyllabic melody pitch in each part. Inaccuracy is the basis of multi-speaking visual lyrics. It is the premise and guarantee for multi-segmental visual lyrics. At the same time, multi-sounding visual sing is also a collective art. Without sounding, there is no multi-sounding visual lyrics. Inverness and harmony colors.

From the point of view of the instrument, the material, structure, and quality of each part of each instrument are important factors that affect its pitch. Different instruments have different materials and structures, so that a variety of musical instruments with different pitches are produced. Changes 
in the structure of the instrument and the quality of the selected material will affect the pitch of the instrument. From the standpoint of vocal tones, each person has different vocal conditions, sound positions, breath, strength, and elasticity of the diaphragm, resulting in different characteristics of each person's pitch. Each person's own conditions determine the pitch accuracy. Accuracy. The vocal control of the pitch is much more difficult than that of the instrument, and the sound must be completely based on the inner sense of music. Only through a solid theory of music learning and repeated practice will the concept of pitch and the grasp of pitch be grasped. There is a certain breakthrough. The discipline of solfeggio is a basic music school, which determines that the students in a class may be different majors, piano, vocal music, theory, orchestra, dance, and so on. Each student has different vocal conditions and different vocal foundations. Therefore, it is necessary to add some basic knowledge of vocal music in the multi-sounding vocal lessons and learn some correct breathing methods and scientific vocalization principles. Some students have good inner auditory abilities, but lack of vocal skills can not accurately express the inner auditory sense, resulting in deviations in pitch. For example, excessive power, loud volume, insufficient breath support, and high or low sounds near the sounding point all contribute to the lack of vocal technology. At the same time, whether or not the posture is correct at the time of singing has a certain influence on the pitch. The posture or stance of the body and the state of the head, abdomen, shoulders, and larynx will make the vocal pitch higher or lower. Therefore, good singing techniques, sitting posture, and positive expression on the face are the accuracy of pitch accuracy.

The most important principle, whether in chorus or multi-part violin, is that we must listen to the pitch of each other voice while singing our own voice. In the single-voice view, as long as we can sing the pitch and rhythm of our own scores, but in the multi-part voice singing, the emphasis is on the group's singing, which is that each part must be maintained in pitch. Unity and balance, this unity and balance must be established on the basis that each singer in each voice listens to each other. In the rehearsal of some not very professional choral groups, we often see some choir members singing and sing the choir and lyrics. The name and lyrics are their own voice, but they should go high to other voices. I am afraid that my own tone will be "run away" by other voices. Some people even plug their ears and fear that other melody will affect their singing. In this way, the principle of harmony and harmony between the voices will certainly be lost. When conducting multi-sounding vocal training, the principle of listening to each other must be cultivated. While singing melody, we must ensure that vocal parts listen to each other to achieve unity and balance of the overall timbre. Only under the subjective conditions of mutual listening, mutual comparison, and mutual convergence, can we constantly adjust the pitch of our voices to achieve an accurate, balanced and harmonious pitch. This is one of the conditions for the formation of a perfect music image, and it is also a multi-tone. An important task of ministry education.

Many of the multi-speaking visual ensembles are made up of classical and romantic piano pieces and music of various nationalities. Many of them have complex musical works. Rhythms, speeds, strengths, zones, etc., are important means of shaping the image of music, but it will give the accuracy and control of the pitch a considerable degree of difficulty. For a multi-part vocal work, if the speed is too fast, the student does not have enough time to listen to it, it will bring psychological tension, and the concept of pitch has not yet been formed in his mind. In this state of singing and singing, neither the oral cavity nor the vocal cords can guarantee the state of relaxation. The singer's name is the same as the jingle style, so that the phenomenon of high pitch will occur. On the contrary, when the singing is too slow, singing The state is not positive, the atmosphere is low and unstable, and the sound is usually low. When the rhythm of the visual singing works is tedious, the singer must analyze the complicated rhythm and try to maintain the accuracy while also taking into account the rhythms of other voices. This gives the singer a feeling of "overwhelming". This is very inaccurate. Easy to stabilize. The intensity is also an important factor affecting the pitch. Some of the sight-singing works that must be vocalized with strong voices will cause the singer to experience a loss of hearing and cannot feel and estimate the rhythms and pitches of other voices, resulting in sounds. Departments interfere with each other, failing to achieve harmonious and perfect pitch, and may even cause the training of multiple voices to fail. The effect of the sound 
zone on pitch is relatively straightforward. Due to the occurrence and commonality of human voices, the vocal cords, the breath, and the emotions are in the most balanced state during the singing of the vocal area. The sound is very stable, and it is difficult to control the timbre of the two ends. The pitch near the vocal area is the most difficult to control.

\section{Conclusion}

Singing practice is a basic course in the music learning process. It is a necessary ability to develop other music subjects before they are taught. Therefore, learning solfeggio is not only necessary for theoretical courses such as harmony, polyphony, and musical analysis. Music performance courses have a very important role. In previous studies of solfeggio, despite the fact that multi-vocal vocals have been mentioned and studied by experts and scholars, multi-vocal vocal teaching has always existed in the solfeggio lessons of music schools, but However, most music teachers believe that multi-sounding is actually a singer's accessory or neglected. For multi-sounding training, it only stays at the beginning of the interval and the chorus of the chords. In the stage.

\section{References}

[1] Cai Jun. Multi-discipline introspection of sight-seeing and ear training classes[J]. Journal of Nanjing Arts Institute, 2004(4).

[2] Li Jinsheng. Interdisciplinarity in the Teaching of Singing and Ear Training in Teachers Colleges[J]. Chinese Music,2003(2).

[3] Zhang Jinong. On the Comprehensive Ability Training in Solfeggio Teaching[J]. Huang Zhong (Journal of Wuhan Conservatory of Music), 2003 Supplement

[4] Wang Weiping. Musical Hearing Representation and Musical Hearing Training[J]. Journal of Hangzhou Teachers College,1999(5).

[5] Wu Haiyan.Talking about Intimacy Training in Visual Education[J]. Journal of Yangzhou Institute of Education,2003(1).

[6] Zhao Gefei. Talking about the Two Singing Names and Their Teaching Methods[J]. Art Research, 2001, (4). 